\title{
Exploring multi-actor value creation in IT service processes
}

\author{
Heikki Lempinen ${ }^{1}$, Risto Rajala ${ }^{2}$ \\ ${ }^{1}$ Department of Information and Service Economy, School of Business, Aalto University, Finland; \\ ${ }^{2}$ Department of Industrial Engineering and Management, School of Science, Aalto University, Finland \\ Correspondence: \\ H Lempinen, Department of Information and Service Economy, School of Business, Aalto University, P.0. Box 21210, \\ Aalto Fl-00076, Finland. \\ Tel: +358403538436
}

\begin{abstract}
Organizational information technology (IT) needs are served through increasingly complex configurations of people, technologies, organizations, and shared information. Ideally, an organizational IT service is valuable for both the providers and users of systems and solutions. However, mutually beneficial outcomes may be difficult to achieve within the configurations through which IT services are delivered. We suggest that analyzing stakeholder interplay in IT service processes helps us to understand how information systems (IS) organizations can be leveraged to co-create business value. Through a qualitative empirical inquiry, we explore IT service realization in two case organizations. Through our analysis we find that value creation builds on orchestrated social action among the different stakeholder groups involved. Joint value creation in IT service processes hence calls for specific network leadership and resource integration capabilities from the IS organization. The paper enriches the current understanding of business value creation in IT services by infusing the service logic with traditional IT management perspectives. The findings highlight that the extent to which the IS organization can learn to facilitate the interaction between the essential actors in an 'IT service system' and leverage user-perceived value throughout the service process will ultimately determine its success or failure.
\end{abstract}

Journal of Information Technology (2014) 29, 170-185. doi:10.1057/jit.2014.1;

published online 25 March 2014

Keywords: IT value; service process; multi-actor system; IS organization; performance management;

dashboard

The online version of this article is available Open Access

\section{Introduction}

T he way in which an information systems (IS) organization creates business value has been a perennial question in IS research since the 1960s (Keen, 1993; Peppard and Ward, 2005). Essentially, information technology (IT) business value has been associated with the IS organization's ability to link the available IT solutions and capabilities to business needs (Guillemette and Paré, 2012). In many organizations, this is indeed a key aspect of the services that the organizational IT function provides for the rest of the organization (Peppard, 2003). To do this, the IT function must be both a facilitator of services provided to organizational users, and an intermediary between business imperatives and external IT resources (Keen, 1993).

The focus of IT management has moved away from pure technology administration towards more comprehensive information management services by which IS organizations offer added value to managers, decision makers, and other users of information (Guillemette and Paré, 2012). More than ever before, these services are developed and maintained with end users and external IT service providers (Peppard, 2003). Although prior literature has explored the role and tasks of IS organizations from several perspectives, confusion persists regarding the ways in which IS organizations create value in cooperation with multiple parties (Grover and Kohli, 2012; Sarker et al., 2012). There is a growing body of research intended to reduce the conceptual ambiguity of value creation in the business and management literature (e.g., Ramirez, 1999; Bowman and Ambrosini, 2000; Lindgreen and Wynstra, 2005; Grönroos, 2008). Mathiassen and Sørensen (2008) suggest that IT business value is created and experienced through 
service realization, and not only as outcomes of IT projects. Similarly, Sandström et al. (2008) underscore that in technology-based services, value is determined by the experiences of individual beneficiaries throughout the service process. Congruently, Stucky et al. (2011) propose that value is often cocreated in a joint activity resulting in mutually beneficial outcomes, but it can be difficult to achieve in IT service engagements. Creating business value through IT therefore calls new management approaches into play. In particular, there is a need to reinvent the IS organization as a nimble, collaborative and innovative service provider. However, the role and tasks of an IS organization in catalyzing value creation in intra- and inter-organizational settings have not been sufficiently explored. Value co-creation processes in IT services require further investigation.

The purpose of this study is to deepen the current understanding of IS value co-creation by answering this research question: How does an IS organization leverage business value creation in multi-actor IT service processes? In our analysis, we focus on a common organizational IT service: IS development. We synthesize theoretical perspectives from previous IS and service management research. We adopt the social action framework by Hirschheim et al. (1991) to explore social interaction in IT services. We also use Newman and Robey's (1992) social process model to analyze the dynamics of stakeholder interplay in IT service realization. To complement our analysis, we draw upon the recent service management literature (e.g., Lusch et al., 2007; Grönroos and Ravald, 2011) by concentrating on the concerted value creation through the exchange of internal and external resources and capabilities. Our empirical data was collected from two organizations that adopted a performance dashboard system as an organizational IT service.

The paper is structured as follows. After this introduction, the next section presents the theoretical background. The subsequent section discusses the research methodology. In the latter section, we present the case analyses. The last two sections of this paper are devoted to discussing our findings and conclusions.

\section{Theoretical background}

\section{Value co-creation in organizational IT services}

Contemporary IS organizations are turning their attention to jointly creating value with a variety of stakeholders, including customers, partners, and other business organizations (Sarker et al., 2012). From the previous literature in IS business value, we know that IT value is synergistically coupled with other organizational development processes. It is also known that IT-based value manifests itself in many forms (e.g., increased productivity, process improvement, innovation, or latent value perception), and that IT value is created on many organizational levels, from individuals to organizations and industries. Most of the previous work on the business value of IT has examined relationships between IT inputs and economic outcomes of the firm (Kohli and Grover, 2008). However, investigating the ways in which multiple parties co-create value remains an under-explored area in IS research. Grover and Kohli (2012) suggest that while the idea of value co-creation is conceptually intuitive and simple, the process through which IS organizations can generate business value is likely to pose several challenges.

In past years, value co-creation has been studied actively in service management and marketing research, particularly after the service-dominant logic (S-DL) of operation (Vargo and Lusch, 2004 and 2008) was introduced. It takes the view that the application of competencies (such as knowledge and skills) by one party for the benefit of another is the basis of value creation (Vargo and Lusch, 2008). The S-DL emphasizes two aspects of the process in particular: social interaction and resource integration.

IT-based value production in multi-firm environments has traditionally been viewed from a resource consumption and transaction cost perspective (Kohli and Grover, 2008). Grönroos and Ravald (2011) suggest, however, that value co-creation is an inherently different form of value production. Value co-creation relies on resource integration and creating valuein-use out of resource sharing. Hence, value co-creation necessitates that stakeholders engage in and become participants in the production process (Grönroos and Ravald, 2011). Furthermore, the current body of service management literature (e.g., Lusch et al., 2007; Grönroos, 2008; Gassmann et al., 2010; Grönroos and Ravald, 2011) suggests that business value at an organization is created through interaction. Prior IS literature has comprehensively studied how interaction between stakeholders, such as IT specialists and business representatives, influence IT project success. There are decades of literature on the social and sociotechnical aspects of IS development and IT project management but no conclusive evidence on how the latent value creation processes are embedded in IT projects and IT services in general. There is undoubtedly much value in the previous theoretical perspectives and models that investigate social interaction in processes that involve multiple parties. In this paper, we utilize two theoretical models to analyze value creation in IT service processes; the social-action perspective by Hirschheim et al. (1991), and the social process model by Newman and Robey (1992).

Both frameworks acknowledge organizational IT as a situated and socially constructed phenomenon (Markus, 2004; Peppard and Ward, 2005) which resonates with the foundational principles of value co-creation in S-DL. The social action perspective builds on the awareness that the primary reason for complexity in IT projects is human activity. In this view, IT solutions are created though processes governed by the social interplay of multiple actors, who attempt to make sense of their own and others' actions largely through the medium of language. Each dyadic interaction between the stakeholders comprises an episode of social action. In these episodes, the stakeholders create consensus (agreement), resistance, or conflict (disagreement) through power, knowledge, subjective meanings, and human interests of the associated parties. Creating value through IT thus depends upon managing a social process in terms of the quality and outcome of the episodes. The social process model explains how and why outcomes are generated as a result of episodes of social action and their sequence in the delivery of IT solutions. The process approach complements the dominant view in service research that characterizes service as a process instead of merely an outcome (Peppard, 2003). 


\section{Re-interpreting IS development through the service logic}

The S-DL views stakeholder involvement in IT-based services through the operation of a service system (Badinelli et al., 2012). A service system is defined as a configuration of people, technologies, organizations, and shared information that creates and delivers services that realize value for both the providers and the users (Maglio and Spohrer, 2008; Qiu, 2009). Drawing on the conceptualization of Vargo and Lusch (2008) and Hirschheim et al. (1991), we investigate value creation among a constellation of actors which we call an 'IT service system'.

All service systems may be viewed as cognitive systems within which knowledge is a 'meta-resource' that is shared in interaction between parties (Badinelli et al., 2012). Congruently, Grover and Kohli (2012) highlight the 'knowledgesharing layer' as a key dimension in IT value co-creation. The integration of needs, resources, information, and objectives among the providers and users of IT require people to interact (Newell et al., 2004). These interactions embed both the knowledge and competencies, and involve the expectations and requirements of the associated parties towards the service delivery process and its outcomes (Peppard, 2003; Mathiassen and Sørensen, 2008). As Edvardsson et al. (2011) point out, knowledge needed in IT service processes is often situational, as is most human knowledge which is developed, transmitted and maintained in social situations (Berger and Luckmann, 1967).

One of the essential purposes of knowledge sharing is to build consensus among associated actors, while knowledge differences between the actors are seen as a salient cause of conflict (Hirschheim et al., 1991). Edvardsson et al. (2011) suggest that consensus, which consists of shared understandings and rules for social conduct, is a vital trait for value creation in any social system. Conversely, conflict between parties in a service system can create resistance in actors' behavior in the service process, which is a barrier to collaborative value creation. In IT services, each stakeholder holds or has access to specific knowledge regarding technology, use context, management, organizational characteristics, and other important information that is necessary for the realization of the service. For example, developing an IT strategy, software system, and technical infrastructure is essentially constructed from knowledge that has been deployed by systems architects, developers, communications experts, and other stakeholders in design and construction (Peppard 2003). A variety in the forms of knowledge held by these actors surfaces in their interactions within the service system.

Furthermore, the S-DL underscores joint value creation through resource integration and the alignment of the interests of the actors involved (Vargo and Lusch, 2008). In other words, all involved parties, including users, are considered active co-creators of value for themselves. This view differs from the traditional functionalist IS development approach (see, e.g., Hirschheim and Klein, 1989), which emphasizes IS as the outcome of developmental, engineering, and formulative activity and perceives users mostly as the targets of action, whose needs the IS organization strives to satisfy. Deighton and Grayson (1995) have argued that according to this view IS benefits are not always shared equally between the provider and the users. Consensus is inevitably formed through a compromise between what the users want, what the company wants, and what the institutional reality allows.

Conflicting interests and knowledge asymmetries are not uncommon in service systems. Parallel with the neohumanist paradigm to ISD (Hirschheim and Klein, 1989), the servicecentric approach seeks ways to overcome the barriers of distorted communication, power, psychological compulsions and social constraints in IT service realization. When the perceived interests of a particular party have not been met, resistance in that actor's behavior might result. However, social power is the ability to call upon and use resources to break such resistance (Hirschheim et al., 1991). A powerful party can coerce less powerful ones to engage with a particular service, even independent of their perceived interest in that service (Standifer and Wall, 2003; Peñaloza and Venkatesh, 2006). Power can be defined simply as the capacity to effect and affect organizational outcomes (Mintzberg, 1983). Power is essentially a combination of processual, institutional and organizational influences that are intertwined (Fincham, 1992).

Stakeholders in multi-actor IT service systems

Stakeholder participation is a widely accepted principle in the development of successful IS (Ives and Olson, 1984). However, equal value can be difficult to gain for all parties involved in organizational IT services, as the participating actors may have different aims and competencies (Peppard, 2003; Stucky et al., 2011). Furthermore, the focal IT management task studied in this paper - leveraging business value through IT services - is inherently complex because it must integrate a great variety of resources held by external stakeholders, technological issues and organizational factors that are often beyond the control of an IS organization (Xia and Lee, 2005). Several internal and external actors all have a role in delivering IT services (Peppard, 2003). In our comprehensive review of previous literature in IT system development, we identify four crucial stakeholders that participate in value creation: IT function, users, IT vendors, and organizational decision makers.

\section{IT function}

Control over IT resources in organizations is typically delegated to the IT function, which provides IT services to the entire organization as a centralized, decentralized or federal entity (Gordon and Gordon, 2002; Guillemette and Paré, 2012). There are several types of IT-related services that are crucial for most organizations, including information management, IT project management, application development, systems implementation, technology maintenance, and training (Peppard, 2003). The role of the IT function in organizations constitutes a central body of research in the IS literature (Guillemette and Paré, 2012). Earlier literature has studied the types of structural arrangements (Sambamurthy and Zmud, 1999; Gordon and Gordon, 2002), forms of governance in IT functions (Weill and Ross, 2005), and the profiles and activities performed by the IT staff, specialists, and managers (e.g., Peppard, 2003). Many past studies (e.g., Venkatraman and Loh, 1993) have also investigated the relationships between the organizational IT function, and other business units and external partners. 
Users

Although users are often experts in their own fields, they may have a range of IT needs that require specific skills and competencies that end users do not often possess. These capabilities are therefore provided to the users by the IS organization. It has been argued that users' needs take center stage in IT service realization, but it is also acknowledged that the task cannot be carried out by IT specialists in isolation (Stucky et al., 2011). Users rather than systems analysts are often the best source of information on how they will use IT. Hence, user participation is widely accepted as indispensable to the development of successful services (Zeithaml et al., 1985; Bitner et al., 1997; Sierra and McQuitty, 2005; Yun Kyung and Menor, 2010), and IT solutions (Markus and Robey, 1988; Orlikowski and Baroudi, 1990; Orlikowski and Gash, 1994). Prior IS research has investigated many aspects of user participation, including the type, formality, and influence of participation (Mumford, 1979), the degree of participation (Ives and Olson, 1984), and the content and extent of participation (Hirschheim, 1983). By the same token, the involvement of users in delivering IT solutions is one of the most important determinants of an implementation's success or failure (e.g., Barki and Hartwick, 1989). User involvement with, for example, enterprise systems and decision support systems development may be more critical than with other systems as information required to build such systems can be obtained only from users (Ives and Olson, 1984). For this reason, encouraging user involvement is especially relevant for higher user-perceived value (Blazevic and Lievens, 2008).

\section{Decision makers}

Organizational decision makers are essential actors throughout the IT service process, from initiation to realization (Armstrong and Sambamurthy, 1999; Luftman and Brier, 1999). Decision makers are actors at several units and levels of the organization, such as line managers, business unit heads and executives who are in charge of a particular function or area of business. However, management of technologyintensive service systems requires tasks and skills beyond the decision maker's capacity (Peppard, 2003). Other specialized actors must therefore carry out these tasks on behalf of the decision makers. In many organizations, these tasks are allocated to the IT function. Although the role of decision makers in IT services is crucial, securing their involvement and engagement in the service realization may be difficult. To this end, Locke and Schweiger (1979) advocate participative decision making, in which managers encourage other organizational actors to make a variety of decisions. Indeed, the locus and distribution of decision-making power regarding IT remains a significant concern in IS research (Sambamurthy and Zmud, 1999; Weill, 2004).

\section{IT vendors}

Supplier-customer collaboration is a key dimension in all service systems, and is most pronounced in IT services, as organizational IT is now more than ever acquired through IT outsourcing and other collaborative arrangements (Lee et al., 2004). In the traditional expert developer perspective to ISD (Hirschheim and Klein, 1989), the system developers are seen as the experts who take the objectives and turn them into a constructed outcome: the system. In the S-DL (Vargo and
Lusch, 2008), the collaborative relationship between suppliers and technology providers is an increasingly important aspect of successful services, as service realization depends upon the utilization of external IT resources. In this view, value is co-created in business-to-business (B2B) relationships between a firm and external technology suppliers (Sarker et al., 2012). Furthermore, many vendors offer IT systems as a service that comprises the offering and expertise of several suppliers, such as IT software and hardware providers, and IT consultants. It underscores the role of change agents who help users and other stakeholders make sense of a service in its environment. Heiskanen et al (2008) argue that IT outsourcing relationships are essentially social processes that are shaped by the involvement of multiple actors over time. From the viewpoint of the IT function, this development has brought greater importance to the tasks of vendor selection, vendor relationships management, and contract management (Peppard, 2003).

In sum, the stakeholders represent diverse groups of individuals including IT staff, users, and their representatives, heterogeneous levels of management as the owners of resources and capabilities needed in an IT service. The stakeholders exchange and develop these resources within a complex, intertwined set of social relationships and interactions, in which they take part in communicative action. In such complex service systems, there is a need for coordinative and emancipative activity, which attempts to unify the various stakeholders' needs and resources in order to effectuate value for all parties.

\section{Methodology}

This research follows an abductive process (Dubois and Gadde, 2002). It blends theoretical knowledge and empirical insight through 'systematic combining'. Thus, the research process comprises both inductive and deductive phases. The inductive phases were conducted using an interpretive case study method (Walsham, 1995). The theoretical lenses adopted from the previous IS literature, the social action framework (Hirschheim et al., 1991), and the process model by Newman and Robey (1992) were used to organize the analysis and interpret the findings. The analytical framework was complemented by empirical insights gained during the process and through an additional theoretical perspective provided by the S-DL (Vargo and Lusch, 2004, 2008).

\section{Case selection and description}

Our empirical inquiry investigates IT service realization in two case settings. We focus on organizational IT service centered on a specific type of information system: performance dashboards. Performance dashboards allow decision makers to monitor and analyze business performance through condensed visual representations of large amounts of data (Eckerson, 2010). Technologically, dashboards consist of a computer interface and a business-intelligence platform (Clark et al., 2007). The interest in developing performance dashboards in an organization is driven by a need to solve routine management problems such as gaining information on the performance of business units for which managers are responsible (Nudurupati et al., 2011). However, dashboards are also deployed at other organizational levels due to the emergence of flat decision-making hierarchies, self-governing 
Table 1 Summary of the interviews

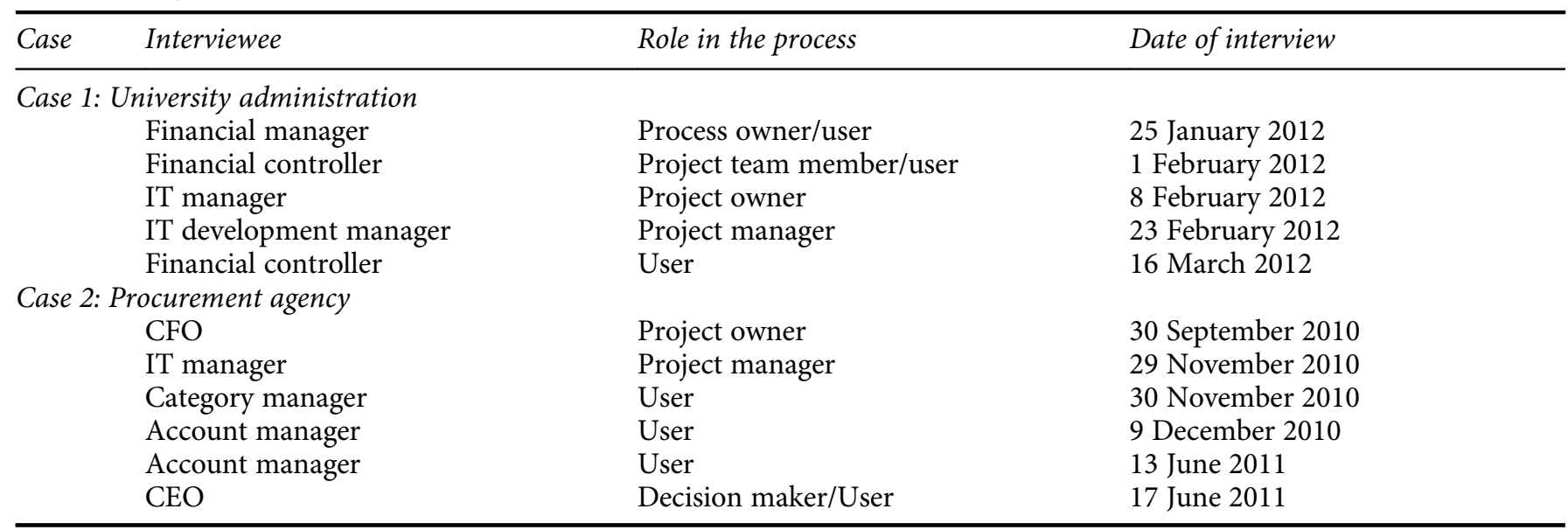

teams and the empowerment of workers (Borgatti and Foster, 2003). Performance dashboard development was selected as the context of this study because it supports organizationwide use and hence its development is typically characterized by the needs, involvement and predisposition of several stakeholder groups rather than single users or departments (Pauwels et al., 2009). Moreover, Pauwels et al. (2009) point out that the development of performance dashboards exemplifies the management of often-conflicting interests among stakeholder groups. In this vein, we believe that the development of performance dashboards offers a fruitful context for the investigation of the social action that takes place within an IT service system.

\section{Data collection and analysis}

The two case studies were conducted in organizations that recently adopted a performance dashboard system. In both cases, the IT function operated as a service provider for the organization and was in charge of managing the systems development project. An interpretive case study method (Walsham, 1995) was used to investigate the interplay among essential stakeholders in both cases. We chose the interpretive stance because it allowed us to access social constructions such as language, consciousness, shared meanings, and other instruments that are needed to understand human thought and action in social and organizational contexts (Klein and Myers, 1999).

The data was collected through face-to-face, semi-structured interviews with key persons in the IT solution-delivery projects in both case organizations. The interviewees included managers, service process owners, and users of the investigated services. Table 1 lists the interviewees and describes their role in the projects. The interviews were conducted pairwise by two researchers. We used a semistructured interview guideline to conduct the interviews (Myers and Newman, 2007). All interviews were tape recorded and transcribed.

The data analysis consisted of interpretation of the data during the interviews, and in-depth familiarization of the transcripts afterwards. Investigator triangulation was used by having two researchers analyze the data. That is, two researchers grouped the findings from each case study individually, and compared the findings of the two cases jointly. Our theoretical framework evolved throughout the data collection period due to the systematic combination of theoretical and empirical knowledge.

\section{Cases}

The S-DL sets forth several principles of value creation through a service. In sum, the principles state that value is always co-created by the actors involved, that value is always uniquely and phenomenologically determined by the beneficiary, and that resource integration is the basis of service processes (Vargo and Lusch, 2008). Following the guidelines presented by Newman and Robey (1992), we explore these aspects within ISD by analyzing the antecedent conditions, critical encounters and episodes, and outcomes of the service realization processes in our cases. In addition, by following the theoretical concepts suggested by Hirschheim et al. (1991), we focused on the ways in which knowledge, interest, and power of the different parties led to consensus, conflict and resistance in the subsequent events. Although subjective meaning is embedded in social action, we have excluded it from the scope of our analysis since it is rather difficult to observe in an empirical context. We use this analytical framework to explore the value creation activity carried out by the involved parties, and to formulate five theoretical insights that are presented in the next chapter.

Figure 1, rooted in the process model by Newman and Robey (1992), illustrates an abstracted view of our ex ante conception of the service realization processes in the cases. The process model highlights two types of events that are critical to the realization of IT solutions and value creation. Encounters are single events that take place at a specific point in time; episodes constitute a stable set of activities over a longer period of time. Encounters precede and succeed episodes. The process is influenced by a set of antecedent conditions referring to the history and reasons behind the system's development initiative (Newman and Robey, 1992). Three phases were identified in the service realization of both cases: initiation, design, and implementation. Similar 


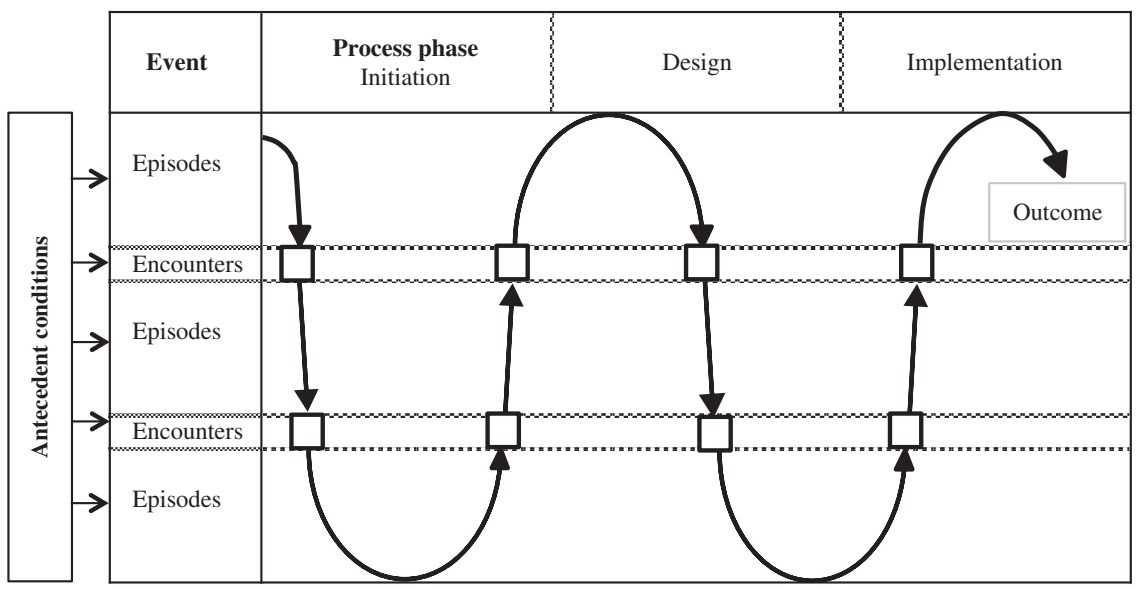

Figure 1 The service realization process.

sequential phases have been identified in previous IS research (e.g. Xia and Lee, 2005). The antecedent conditions and events together contribute to the process outcomes. Processes may be user-led, analyst-led, or joint-development, according to how they are managed (Newman and Robey, 1992). In our analysis, we concentrated on the involvement and interaction of four essential stakeholder groups: IT function, users, decision makers, and IT vendors.

The key episodes in the process are illustrated in Figure 1 with the curved arrows representing time periods during which the service is realized. The social encounters occur between episodes when the stakeholders interact. Different forms of social interaction exist during the episodes as well, but the encounters represent notable situations of interaction, which take place at a specific point in time. The process eventually leads to an outcome, in this case, the information system in organizational use. In addition to the value of the outcome, we are interested in the value perceived by the actors involved in the process.

The most important encounters are marked with labels en1-en6 in the following case analyses. The episodes that follow each encounter are not marked or numbered in the interest of clarity.

\section{Case 1: An organizational performance dashboard solution for university administration}

\section{Antecedent conditions}

The setting of the first case study was a Northern European university that was established in January 2010 through the merger of three local universities. The university enrolled 17,000 students, 4300 faculty and staff, and graduated 2200 students with master's degrees each year. The university integration imposed considerable pressure on the administrative functions, especially on the IT function. A total of 74 IT projects were started during the merger. The university administration needed a system to monitor the performance of the new university and to lead the associated organizational change. Relevant information was to be drawn from financial systems, HR databases, and the student register. To obtain the information, the IT department first needed to set up a centralized database to gather and store data from the different sources, and then build an interface to provide users with access to the performance information.

\section{Service realization}

The need to develop a new performance management solution was identified by the university management, who delegated the task to the organization's newly established IT function. Since the university administrators were in a hurry, project planning was carried out in isolation from the rest of the organization. The project was initiated with little preparation (en1). The users, apart from a few managers in the central administration, were not consulted at this point, even though the system was to be implemented organization-wide. An episode of confusion followed, as the IT department did not have clear understanding of the university management's expectations of the service and had received hardly any input from the users. As a result, a performance dashboard centered on administrative reporting was deemed a suitable IT solution:

We chose the system without knowing what was actually needed. But we knew that we needed to have a system nevertheless. (Process owner/user)

The IT department prepared a request for proposals to find a suitable technology supplier for the system (en2). The tendering procedure yielded responses from only two vendors, the offerings of which were based on the same software product. Thereafter, the users were given a chance to evaluate the offers (en3), but left feeling that they had little say in the final choice of the external service provider.

The design phase that followed supplier selection was characterized by a tight project schedule, IT-driven project management, and one-sided user participation. Although both the IT personnel and the users were represented in the project team, the actions and decisions were driven by the interests of the IT department. Most user groups, including representatives of top management, were not actively involved in providing input for system design. This led to a widening disparity of knowledge among the organizational actors who were to be the users of the system. From a project management perspective, the process flowed in a seemingly efficient 
manner and no conflicts between the parties involved were observed during this episode.

However, it was later observed that knowledge differences and miscommunication between the IT department, IT vendor, and users had unexpected consequences in the system implementation phase. The main problems were that the users remained unaware of the full capabilities of the system, and that the IT department was unable to share the technical knowledge with the users. Instead, the users requested features from the new system that the previous financial reporting system already provided. Consequently, the user requirements provided to the IT vendor were based on biased information (en4). As the project manager explained:

In a way it was very good that we had users involved, because we were in a hurry .... One thing that I regret afterwards is that we made the specifications too precise, especially by determining too strictly what the reports should look like [on the basis of existing financial reports].

Although the IT department and users communicated rather closely on the business needs and the features of the intended solution, the IT vendor operated on its own. There were no face-to-face meetings between the users and the vendor, because the vendor's premises were located in another city and the client organization's employees were expected to use teleconferencing. Consequently, the users had difficulty communicating with the vendor. Moreover, there were problems among the vendors to whom the IT department was outsourcing IT development.

As the project deadline approached, the team did not have time to conduct sufficient testing prior to implementation. Problems ensued, and the service realization culminated in a conflict among the stakeholders, as the vendor failed to meet the client organization's expectations and the IT organization was not able to trigger a consensus between the parties. The completed system implementation project missed the original deadline of January 2010. The financial reporting capabilities were in place organization-wide, but the dashboard solution was not.

\section{Outcomes}

The communication problems between the IT department, university management and the IT vendor created difficulties in managing the expectations of several stakeholders at the time of delivery of the solution (en5). The vendor was uncertain about the university's expectations. Ultimately, the outcome did not satisfy the decision makers, as it exceeded the budget and the vendor was unable to keep its original promises. As the project owner explained:

The vendor advertised that their system can be implemented in hours compared with other dashboard solutions. In our case, it took much more time and money than what was expected.

Furthermore, the following encounter (en6) featured a clear clash with the users' expectations. The finance department expected a more sophisticated financial reporting system, but the technical solution did not meet their reporting needs. The solution also failed to meet the needs of other user groups, and disappointed top management's expectations of organizationwide performance management. Instead, the service was implemented predominantly on the basis of the financial department's needs and IT-led requirements engineering. Although the users had no role in the system initiation, and many of them were not involved in the development at all, the new system was expected to be used by several organizational functions. Consequently, strong user resistance to the system and poor user perceived value of the IT service were observed during the subsequent episode. From the vendor's perspective, this conflict was unforeseeable, as it was in their primary interest to deliver a system that satisfied the requirements as spelled out by one of the project team members representing the IT department:

Software vendor did exactly what we asked - we got a [financial] report, exactly according to the specifications.

As depicted in Figure 2, the IT service realization in the university administration case comprises a rich set of interactions that formed parallel and overlapping sub-processes.

In contrast with the classification proposed originally by Newman and Robey (1992), we identified and labeled the

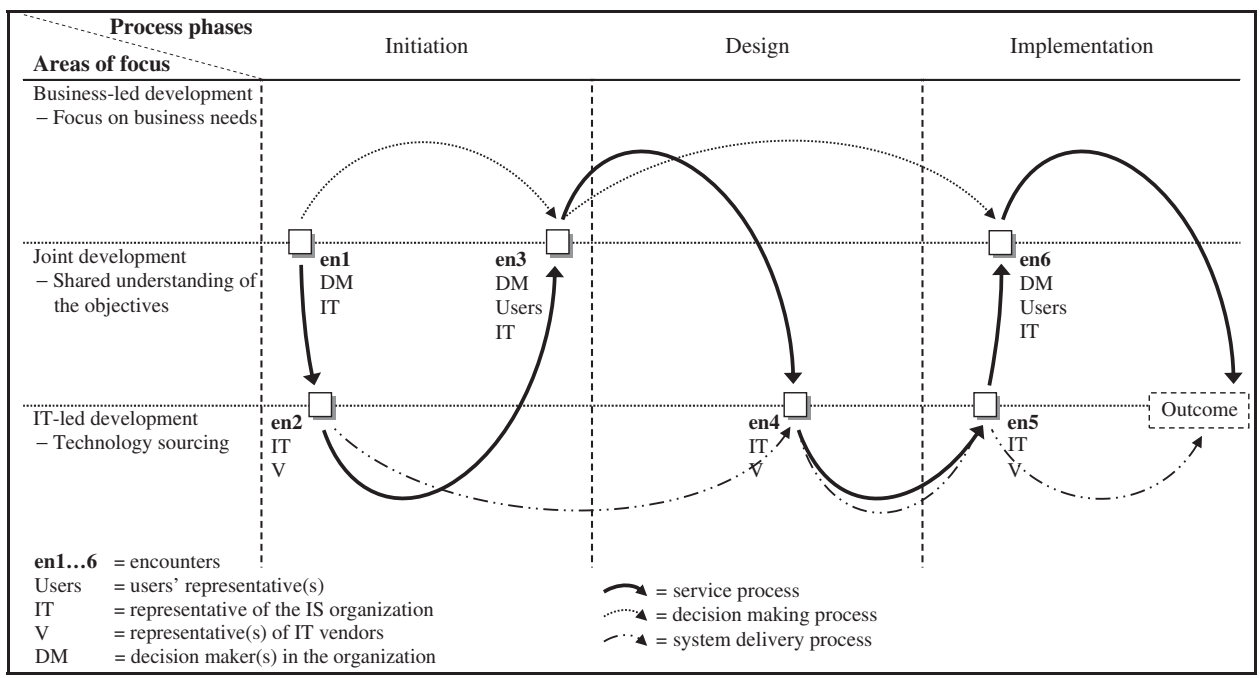

Figure 2 The process of IT service realization in the university administration case. 
user- and management-led approaches together as a businessled approach, because the managers in the organization were also users of the IT service. Hence, they had a dual role as managers and users. For the analyst-led approach, we used the term IT-led development. In this case, the IT organization tried to mediate among the IT vendors, decision makers, and the users. However, most of the processes of decision-making and system delivery took place in isolation. Even though the users participated in some of the encounters in the service development process, they never really interacted with the IT vendors, nor were their desires truly understood by the other stakeholders. The data shows that this was one of the reasons why users resisted the system, and why they failed to see how the system was going to serve their business needs. Throughout the initiation, design and implementation phases, the system delivery process exemplifies a purely IT-led process, without sharing the understanding among users, organizational decision makers and the IT vendor.

\section{Case 2: A purchasing performance dashboard at a procurement agency}

\section{Antecedent conditions}

The second case example takes place in a governmental purchasing agency in a Nordic country. The procurement agency negotiates and maintains purchasing framework agreements, which are used by publicly owned enterprises, and governmental units such as ministries and state agencies. The procurement agency specializes in tendering for the purchase of goods and services, and administers contractual procedures. The case organization employs 60 experts in procurement, law, and other areas in purchasing and supply chain management. At the time of data collection, the procurement agency was responsible for facilitating a considerable share of public sector procurement in its country. The purchase volume channeled through its purchasing frame agreements reached $€ 553$ million in 2010. The agency had experienced problems with its previous spreadsheet-based system through which it monitored and reported the extent to which the agency was attaining its objectives. Hence, the company decided to implement a system that would improve the efficiency of its performance management and analysis, as well as enable a more convenient purchasing process for the experts responsible for the contracts.

\section{Service realization}

The service realization process at the procurement agency was initiated as the users actively adduced their needs for improved purchasing and analysis processes. In addition to mapping the users' needs for novel technology, the organization's IT department looked for IT solutions that would contribute to the organizational IT service offering. The dashboard service realization began with an agreement between the IT department and the users that there was a clear need for a better performance management system (en1). Thereafter, the IT department started searching the market for suitable solutions. The IT department's activity was guided, in the first place, by the users' needs during this first episode. The user participation is explained in the following statement from one of the users:

One of our colleagues was there as a representative from our side. ... He knew our needs and ... told the project team what we would appreciate.
Along with the search process, the IT department learned about a potential performance dashboard solution that would meet the organizational needs as expressed by the users. Furthermore, the IT department found a suitable vendor. The IT department and the vendor were quick to reach a consensus pertaining to the process-related challenges the procurement agency was facing and the opportunities that the intended improvements of the process would create. A mutual understanding of the technical imperatives and the institutional constraints in the organization was reached through a consensual communication between the representatives of the technology vendor and the IS organization (en2).

The IT department decided to implement a pilot system before taking further steps in the process to avoid misplaced investments. This pilot system had two purposes: (1) it was a way to gain knowledge about the feasibility and usefulness of the solution, and (2) if it showed potential benefits, it could be used to demonstrate the system's capabilities to the decision makers in the organization. By doing so, the IT department was able to avoid potential conflicts between the users' needs and the chosen system solution, while obviating any resistance among decision makers towards the associated IT service. It was also an attractive approach because the vendor was willing to implement this part of the service at a relatively low price, after which the client organization could retain the contract if needed. The pilot system was introduced in a demo session with the procurement agency's key decision makers and the vendor's representatives (en3). As a result of this encounter, the decision makers of the procurement agency were convinced about the benefits of the solution and its realization as a service:

\section{After [seeing] the demo we wanted it. (Project owner)}

The IT department, IT vendor and the users continued to collaborate on designing the features of the system. Active communication between the case organization's project team and the vendor's technicians and consultants took place during this episode. Consensus among all parties was pursued by carefully selecting the representatives of all user groups to the project team. Some of the primary users even attended the software coding sessions with the IT staff and the technology vendor's representatives. The vendor did most of the actual coding work on the procurement agency's premises, which enabled continuous interaction between the developer and the users. In the following encounter (en4), users' needs were formalized to system requirements to guide the implementation of the IT solution. Importantly, the project manager had learned during that time that user participation in the realization process did not automatically ensure a successful outcome. Of note, the IT department identified some knowledge asymmetries between the users and the IT vendor over the new solution and the system that had previously been used in the organization for the same purpose. For this reason, the IT department needed to improve the users' understanding of the system's capabilities:

It was actually very hard to even get them to understand what kind of other possibilities we maybe have, because three years ago the pivot table was the greatest thing they had ever seen. (Project manager) 
Once the users came to appreciate the potential value of the system, they actively requested the inclusion of the new features and functionality in the final product.

\section{Outcomes}

Once launched, the solution was rapidly adopted by both decision makers and users. The case highlights that emancipative activity by the top management, and direct social interaction facilitated by the IS organization supported mutual understanding among the stakeholders regarding the goals and expected deliverables of the IT service. A close relationship between the vendor and the client organization characterized the process. The procurement agency spent a considerable amount of time specifying the features of the system in use, after which the implementation took only 14 days (en5). This was a pleasant surprise for the decision makers and users alike:

I have never seen an IT project like that because it was so fast. It really included everything that was promised. Although the schedule was tight we managed to do it in time, and the end solution was great. (Project manager)

After less than a year of operation, all members of the organization had access to the purchasing performance dashboard. As the service realization was driven by the users, resistance to its adoption was not to be expected when it was implemented in the organization (en6). Still, having encountered strong user resistance in many IT projects before, the project owner was surprised at how quickly the organization adopted the dashboard.

Figure 3 illustrates the social process of IT service realization in the procurement agency case.

Our data shows that a joint mode of operation dominated the service development process, especially in the design and implementation phases. In the initiation phase, the system delivery process was focused on the dialogue between the users and the IT department. In the design phase, from en 3 onwards, all stakeholders interacted. The decision makers entered the process at en3, after which the decision-making process moved forward in the area of shared understanding. The design phase manifested a joint development process, facilitated by the IS organization. Thereafter, the IT vendor implemented the technical solutions in a reflective manner with the IS organization, and was sensitive to the emergent needs of users. In the implementation phase, the service development is characterized as an IT-led process.

\section{Analysis and findings}

Our empirical study investigated value creation in two multiactor service systems centered on developing organizational IT solutions. We identified four main stakeholder groups: users, organizational decision makers, IT vendors, and the organizational IT function. We analyzed the dynamics of stakeholder interplay across the service realization process, from initiation through design and implementation. Our empirical study investigated two separate cases that represent such processes. One of the cases, a dashboard solution for a university administration, illustrates the process in a public not-for-profit organization, while the other case reviews a dashboard solution at a procurement agency that was a public utility centered on tendering and contractual procedures related to efficient purchasing of goods and services. In this section, we discuss the findings on the observed aspects of value creation across our cases.

The two projects had similar antecedent conditions but the roles of the stakeholder groups and the characteristics of the service processes varied notably. Several modes of development were identified, and these were categorized in our analysis as business-led, IT-led, and joint development. The cases differed in how the associated parties approached the building of consensus on development initiatives, targets, and activities. The university case featured a rather managementinitiated and business-led process at the beginning, but then it was transformed into an IT-led process after the initiation phase. The procurement agency case started from a businessled initiation of the service that was focused on the users, but then became a process of joint development in which the IT vendor was closely involved. Furthermore, the observed

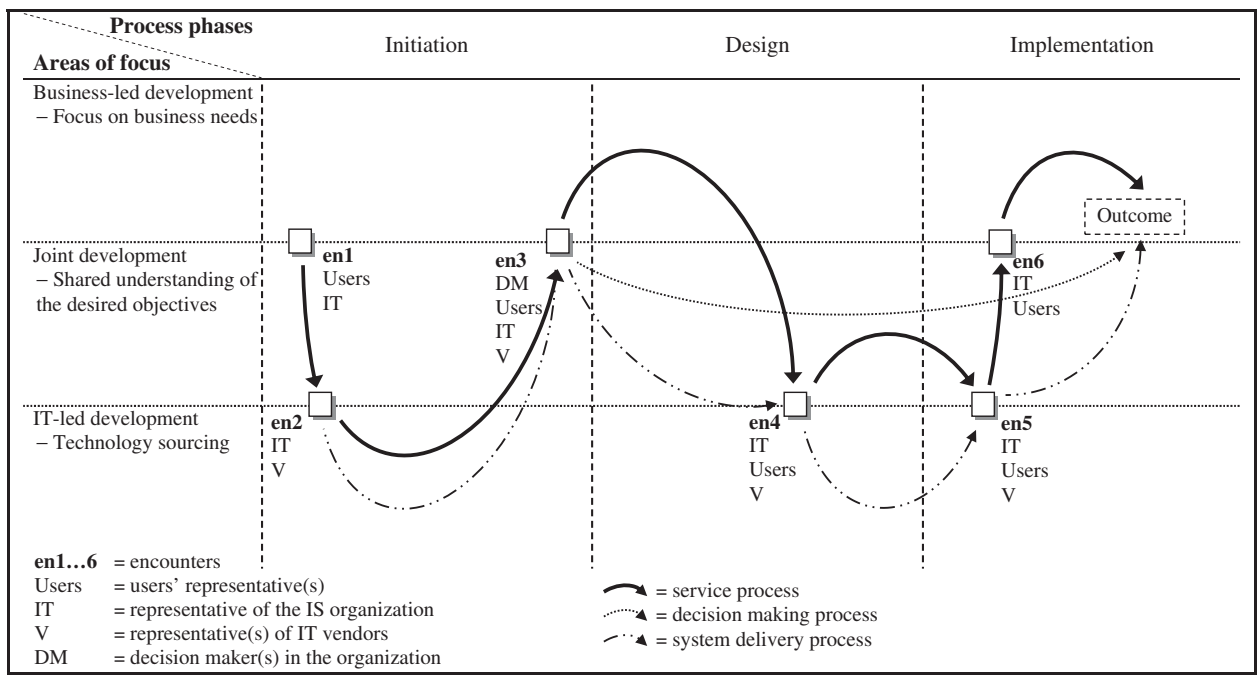

Figure 3 The process of IT service realization in the procurement agency case. 
outcomes were very different, particularly with regard to the perceived and measurable value that was realized as an outcome of the service provided by the IS organizations. Based on the analysis, we observe that the procurement agency case was a rather successful one as the service brought clear quantifiable benefits to the organization after the solution was implemented. In the university case, the delivered solution failed to meet the desired objectives and this did not bring the expected business value to the organization.

Our analysis of the cases was guided by Hirschheim et al.'s (1991) social action perspective and the social process model established by Newman and Robey (1992). We used these theoretical lenses insofar as they supported our analysis of the social interaction in the IT service processes. However, in view of the fact that these perspectives do not fully explain business value creation through IT service, we continued interpreting our findings using the S-DL suggested by Vargo and Lusch $(2004,2008)$. On the basis of our empirical findings, we use these theoretical lenses to encapsulate two fundamental insights of value creation through IT service.

Insight 1: Value creation in IT service is interactional and process-based.

Insight 2: Individual-level value perceptions drive the realization of output business value for the entire IT service system.

In response to the question of how the IS organization facilitated business value creation in our cases, we found that the value experienced by the stakeholders - especially by the users - during the development process predicted the output business value of the solution. Our cases demonstrate that if the key stakeholders perceive that their essential needs are going to be satisfied by the IT service, they will be more likely to invest their time and effort in ensuring that the solution will bring value to the organization when it becomes part of the everyday work processes and organizational structures. While this finding arises from our cases on organizational ISD, it may be relevant across a larger scope of IT services.

Leaning on the conceptualizations by Hirschheim et al. (1991) and Vargo and Lusch, (2004), we next discuss how IT value was co-created through the alignment of (1) mutual interests, (2) the power structure, and (3) knowledge sharing throughout the IT service processes. After each of these aspects has been articulated in some detail, we provide a theoretical interpretation of the potential consequences for both future research and practice.

\section{Mutual interests}

The alignment of interests among stakeholders was identified as a key factor that influenced the perceived value of the IT service in the cases. Even though the way in which the IS service was organized in the two cases was rather similar, the procurement agency case differed from the university administration case from a service value perspective in the early phases of the project. The main difference was that the center of interaction in the procurement agency case was the establishment of an explicit mutual understanding of how the solution would cater to the organization's best interest. In that case, the users' interest and needs were cultivated throughout the process. In the university administration case, in turn, the interests of the decision makers initiated the project after which the IS organization's interest dominated the development process. Moreover, the interests of relevant users were largely neglected. As a consequence, the delivered system offered little additional benefit to the users and the IT service failed to create the expected business value for the organization. However, the procurement agency achieved direct business value from the implemented solution. The resulting dashboard enabled users to improve their working efficiency and to provide better customer service with the timely information they could produce through the system.

These findings suggest that the way the IS organization manages to get in and maintains a dialogue with the users to learn from their experiences and practical needs, will determine how valuable the users perceive the IT service to be. Hence, consistent with the previous literature, our findings endorse user participation as an important driver of success in IS development. However, our findings emphasize that user participation itself is not sufficient to guarantee that the users' interests will be served. Instead, IS organizations should give users the service that they perceive as valuable at the time the service is realized. Such perception of value is gained, according to our analysis, by involving the users only in the most relevant service encounters and by convincing them that their interests and opinions have been respected. Furthermore, clear articulation of the projected objectives is needed for the alignment of interests between external vendors and the client company. This was crucial to the construction of shared understanding in our cases. However, creating strict system requirements in the initiation phase does not serve this purpose in the best possible way, as was observed in the university administration case.

In sum, we see that the IS organization should facilitate the cognitive work underpinning the development of shared understanding, and help the participants to see their individual needs as part of the whole. Importantly, the role of an IS organization in a multi-actor IT service system is to facilitate direct social interaction among the stakeholders. The IS organization should orchestrate social interaction by apprising the essential stakeholders of the critical events in the service development process. Our data gives rise to the understanding that this alleviates the creation of true consensus of both the essential business needs and the IT imperatives. From this observation we postulate the following:

Insight 3: The key task of an IS organization is to enable direct social action within an IT service system to drive stakeholderperceived value.

\section{Power structure}

The formal and informal power structures among stakeholder groups influenced both the service realization process and the experienced outcome in our cases. Formal decision-making power was particularly salient in the initiation phase of the processes as the decision to invest in new systems required top management's approval. In the university administration case, the IT department and the users were not consulted in the initiation phase, and the investment decision was based primarily on top management's judgment. In the procurement agency case, no single actor dominated the process but a more consensual view was achieved in the encounters that involved multiple actors. The IS organization did not challenge the 
power structure but instead, aimed to ensure that the powerful party (decision makers) made the 'right' decisions in the initiation phase and continued to provide support throughout the project. Achieving this state of affairs required the IS organization to identify the desired objectives for development that could add business value for the whole organization. As a result, the IT investment brought a substantial payoff to the decision makers, as the organization was able to save up to two weeks' workload for about 10 employees in the finance department every month.

According to previous literature, if a party occupies a dominant position in decision making, it may make choices that bring the greatest expected value from that party's perspective (Sawhney and Parikh, 2001; Standifer and Wall, 2003). We found that in our cases, no single party had dominated all issues. For example, the decision makers cannot force the users to adopt IS in their everyday work. An instantiation of such informal power among the users was most pronounced in the university administration case. Our findings demonstrate that the IS organization may prevent such behavior in IT services by acknowledging the formal and informal power structures and by orchestrating the decisionmaking processes in a manner that makes the best use of these structures. For example, the IS organization may not be able to coerce the decision makers to invest in particular IS initiatives, but as the procurement agency case shows, it can encourage decision makers to take action by illustrating the potential benefits of the solution.

Moreover, the power structure in an IT service system is often asymmetric. The business value in such circumstances depends on the way the dominant party in each phase perceives the value of the IT service. Our findings underscore the importance of maintaining a balanced collaboration among the actors. We suggest that such collaboration necessitates network management and coordination acts by IS organizations. Organizational decision makers may be especially powerful in the initiation phase, the IT vendor in the design phase, and the user in the implementation phase. Hence, the IS organization should ensure that the dominant party at each phase makes choices that will deliver the greatest expected value to the business as a whole. However, the IS organization has no direct control of the stakeholders' actions in these critical phases. Based on this discussion, we suggest the following:

Insight 4: IS organization can leverage valuable synergies within IT service systems through decisional coordination and emancipative activity.

\section{Knowledge integration}

The importance of knowledge integration throughout the process was emphasized in both of our cases. However, our analysis illustrates that the focus should be on the quality, not amount or frequency, of knowledge sharing activity between the parties. In the procurement agency case, the IS organization coordinated multi-actor interaction in a manner that the knowledge held by different parties was made visible throughout the service realization process. This helped create a consensual view of the parties' essential needs and competencies. In the university case, communication was more reciprocal. That is, knowledge sharing took place almost exclusively between the IS organization and the party that was involved in that phase. Hence, the IS organization tried to act as a knowledge intermediary between the actors, but it failed to disclose some important details about the solution to the concerned parties. Consequently, even though the stakeholders had, at times, a seemingly consensual view of the project, they took the development in a direction that did produce a less-than-satisfactory solution. As the information did not flow properly, the parties did not understand the objectives and potential benefits of the desired outcome in the same way.

Earlier IT management literature (e.g. Peppard, 2003) suggests that stakeholder interaction embeds potential knowledge gaps throughout the development processes. Our analysis adds to this view by proposing that knowledge gaps between the users and other stakeholders are the result of mismanaged social action. In light of our data, the IS organization has a crucial role in closing these gaps, most notably by facilitating direct social interaction among essential stakeholders. We see that a true consensus of the tasks, responsibilities, and objectives may be achieved by involving several parties in the encounters, as was observed in the procurement agency case. Our data underscores that this bridging is especially important in the project initiation and system design phases. From the business value perspective, knowledge sharing during service realization processes seems to be a key determinant in generating positive returns on the investments made, but it may also bring other intangible benefits to the organization. In the case of dashboard development, for example, stakeholders may gain extra benefit from an improved shared understanding of their organization's strategies, goals and performance measures.

Our findings in relation to knowledge integration are consistent with earlier literature (Locke and Schweiger, 1979; Groen et al., 2012) in that user participation is more likely to improve user satisfaction and productivity for those decisions where the end-user has prior expertise or knowledge of an intended solution. However, both of the case organizations encountered problems in making users' knowledge and competencies visible in the development processes. Through the S-DL lens, knowledge sharing that happens in the IT service process is part of resource integration, which is a fundamental part of value co-creation in a service process. Sandström et al. (2008) claims that much of the knowledge needed in value cocreation resides among users who are not always present in the service situation or who probably do not actually use the service (being thus ex situ), but who have previous experience from a similar situation or resource context (in situ). Therefore, in addition to facilitating direct social interaction among the participants for knowledge sharing, the task of an IS organization is to mediate the integration of knowledge resident in the users' as well as other stakeholders' specific contexts. Part of the knowledge may thus be gained from users' recollections of their previous service experiences. As many IT solutions are acquired from external sources in organizations' pursuance of effectiveness, knowledge sharing should be practiced in a way that ensures that the most relevant knowledge and best capabilities are in use, and that the intended solutions meet the desired objectives. In other words, the IS organization should make the stakeholders' specific knowledge and capabilities visible in the interaction. This aids the organization in making use of the best available 
resources for leveraging business value from IT services. Hence, we formulate the insight as follows:

Insight 5: IS organization maximizes the value of individual IT service system participants through knowledge resource integration.

\section{Discussion and conclusions}

This paper presented novel research findings on how IS organizations facilitate the creation of business value in IT services. The study deepens our understanding of the phenomenon in a multi-actor setting termed IT service system. In an increasingly networked service environment, the IS organization cannot deliver business value on its own. Instead, the IS organization is leveraged to co-produce business value with multiple partners. The concept of service systems provides a viable vantage point from which to understand the challenges of value creation in the multi-actor setting. It shifts the view from a single actor's value-creating activities to understanding how value is co-created through an ensemble of actors. Moreover, offering IT as a service shifts the emphasis from the IS organization's internal capabilities to making use of the stakeholders' external capabilities. This notion is highlighted in our cases, as the feasibility of the IT solution in use depended upon the input of several interacting parties throughout the service realization process. Our findings indicate that by maintaining a close relationship with the users, IT vendors and decision makers throughout the process, IS organizations could prevent conflicts arising from unrealistic expectations, miscommunication and asymmetric information between the stakeholders.

Our research identified some essential aspects of value creation through social action in the IT service context. We see that the IS organization creates value primarily by facilitating the interaction between the involved parties - an IT management competency that varied significantly in our cases. In the procurement agency case, the IS organization had a key role in coordinating the interaction among all stakeholders and in involving them in the most relevant process phases. In the university administration case, in turn, joint understanding of the goals, options and realization of the IT solution were accomplished through dyadic interactions between the IS organization and other stakeholders, reflecting a traditional contractor-buyer relationship. In the procurement agency case, the key actors had social interaction with all the actors in at least one joint encounter; this was not observed in the university administration case. In the end, the university administration case failed to reap the expected benefits and business value, whereas the procurement agency case benefitted the organization and yielded a substantial payoff to the investment.

Based on these findings from the cases, we argue that the task of managing the entire IT service system is one of the most salient activities in the service that an IS organization delivers to the rest of the organization. Aligning the needs, goals, and interests of each stakeholder in the initiation phase of a service realization process seems to lead to improved performance in designing the actual solution. Furthermore, our data suggests that multi-actor encounters in the design process enable smoother transition to the implementation phase than did closed interaction between specialized experts and single stakeholders.

\section{Theoretical implications}

The main contribution of this paper is to deepen our understanding of the role and tasks of an IS organization in creating business value in partnership with multiple parties in IT services. Our findings contribute primarily to the IT management literature, but the service management literature beyond IT services can also benefit from our analysis as IT services offer a fertile context in which to study the social processes of value co-creation.

Our findings imply that the creation of business value through IT service cannot be understood only by looking at the outcome. Instead, value creation takes place in complex interrelated collaborative processes, as suggested in our Insight 1 . That is, whereas prior IT management literature has focused on the business value of IT as an outcome of IT service implementation (e.g., Peppard and Ward, 2005), we suggest that an IS organization should facilitate value cocreation throughout the service realization process. To this end, we adopted the social process model proposed by Newman and Robey (1992). We found it helpful to depict and analyze the process at an abstract level and identify several approaches to value creation, such as business-led, IT-led, and joint development processes. However, the model falls short in explaining how an IS organization can facilitate value creation in a multi-actor setting, which was our main research question.

Our cases reveal that value co-creation takes place in social encounters. To investigate the social interaction in multi-actor service systems more thoroughly, we utilized the social action framework, which suggests that conflicts between the associated parties in a system development project (e.g., conflicts over technical quality) can lead to resistance to the use of a system. One of our key contributions is based on the discovery that resistance might also arise in the absence of apparent conflict, but rather when there is a 'false consensus' among the associated actors. This seemed to be the state of affairs in the design phase of the university case. This biased consensus might exist as a result of knowledge differences between stakeholders or because of shortcomings from a mediating actor, in this case the IS organization, and its ability to facilitate knowledge sharing between the actors. Importantly, our findings underscore that such a state may be unnoticed during the service realization process. All parties might therefore believe that good service is being provided during an IT project, yet the outcome may face resistance among eventual users and hence realize unsatisfactory outcome value to the organization.

Compared to the views of Newman and Robey (1992) and Hirschheim et al. (1991), which are commonly used in IT management research, the S-DL perspective goes deeper into the understanding of value as a contextual and experiential phenomenon (Chandler and Vargo, 2011). Therefore, we borrowed the lens of the S-DL (Vargo and Lusch, 2008) to look even more closely into the mechanisms of value cocreation in IT services. The S-DL puts forward some fundamental premises to value co-creation and resource integration. First, it suggests that value is always phenomenological and uniquely determined by the beneficiary. Our cases underscore 
that an IS organization co-creates value with the users by managing an IT service process during which the users find that their needs are being recognized and valued, as suggested in our Insight 2. In addition, organizational decision makers discover business value in an IT service when having confidence that the IS organization will provide the organization with best possible IT solutions. Collaboration between the IS organization and the external parties should generate equal perceived value for both parties throughout the process. Onetime benefit gained by either of the parties on the expense of the other will complicate the maintenance of a healthy and valuable long-term supplier-customer relationship. Even more importantly, our findings suggest that the way the users and other stakeholders perceived the value of the service during the realization processes was a key enabler of an outcome that brought business value to the entire organization.

One of the key issues in this regard, as we suggest in our Insight 3 , is that making the different parties' interests as common property helps tremendously to streamline the objectives of the service. To this end, although the ISD literature has emphasized the mediating role of an IS organization between the actors involved in a system development process, we see that in a multi-actor service system, the IS organization should enable direct social interaction among the essential stakeholders. This notion stresses the central role of the IS organization as a moderator that facilitates the interaction between relevant actors throughout the service processes, from initiation to implementation. Furthermore, our findings highlight the role of an IS organization in coordinating the service system as a network of actors (as suggested in Insight 4). In particular, our study identifies the power structure of multi-actor IT service system as an essential domain of value co-creation (and destruction).

According to the S-DL, value creation is inherently based on the exchange of resources, such as knowledge and skills. Our study adds to this knowledge by shedding light on resource integration processes in the IT service context. We see that value co-creation in IT services is indeed centered on resource integration between the actors involved, as suggested in our Insight 5. In our cases, the resources held by the parties consisted for the most part of intangible capabilities, such as the capabilities of the users and decision makers, the technology-related knowledge of the IT vendor, and the project management capabilities of the IS organization. We observed the exchange of these resources between the parties especially in the encounters organized by the IS organization. Predictably, the parties perceived the resource exchange as valuable if it advanced the accomplishment of their individual desires. To this end, we proposed that pursuit of true consensus by making stakeholders' knowledge visible may help with the development of IT solutions that satisfy all stakeholders equally.

\section{Practical implications}

The present study makes important contributions to the practice of IT management by providing a novel view of the ways in which IS organizations generate business value in IT services. We propose that it is essentially a task of managing a service system comprised by the interaction of several interrelated parties. Frameworks such as ITIL have given IT professionals an understanding of the basics of service orientation, but have fallen short on how to co-create business value with key stakeholders. In this regard, our study identified some crucial tasks for the IS organization.

First, our study highlights one of the grand challenges in managing IT as a service - successful facilitation of the business-IT dialogue among the stakeholders involved. Different approaches to achieve consensus in the IT-business dialogue were identified in our data: a business-led approach, an IT-led approach, and joint development. No one approach was found to be inherently better than the others, but superiority may depend on the organizational context. Each approach calls for a different set of management activities. A commonly suggested solution to mastering the business-IT dialogue centers on involving stakeholders in the development of IT solutions. However, our findings suggest that not all parties should be involved in all encounters. Excessive social interaction could lead to confusion and misuse of resources. Conversely, important actors should participate in critical interactions. In that way, user and organizational needs will be taken into account and will guide investment decisions and system specifications. To this end, our data leads us to conclude that the IS organization should act not only as an intermediary or knowledge broker among stakeholders, but instead, it should facilitate direct social interaction among the parties involved. The difference in our cases show that the quest for consensus among the stakeholders over the desired objectives and the ways to accomplish them can be achieved and maintained only if the parties interact directly, not only through an intermediary.

Second, we see that IT service realization calls for network leadership and coordination to create and maintain a consensus in the service system. As multi-actor IT service systems include autonomous actors, which are beyond the direct control and decision-making power of the organizational IT management, the IS organization needs to emphasize coordination rather than control. Such a strategy is indicative of the need to manage boundary-crossing organizational, functional and cultural activities. If an IS organization is to orchestrate an entire service system, those boundaries cannot be allowed to become barriers to value creation. Our study shows that key tasks of the IS organization include the management of multi-actor collaboration through indirect leadership of the actors. Knowledge of the available options, translation of different parties' imperatives to a shared vision of the service, and unification of the independent actors' interests in the realization of the service are essential challenges for the IS organization. In practice, this means influencing the independent actors towards collective aims instead of local and sub-optimal goals. In addition, it means overcoming any behavioral resistance of the autonomous actors by arriving at a shared understanding of each party's interests in the process. Our findings give reason to suggest that such behavior may lead to greater value in the social context as perceived by all the involved parties. For this reason, we suggest that the ultimate business value to the organization is higher when all essential stakeholders gain value during the service process, are committed to the development of the IT service and support the use of the outcome.

Third, our findings demonstrate the importance of mastering the infusion of both internal and external capabilities for business value creation. The IS organization has a key responsibility in managing the relationships with external 
parties by choosing the right suppliers, acquiring suitable systems and services, and managing the contractual relationship with the vendors throughout the initiation, design and implementation phases of the service realization process. Similarly, the IS organization has to master the use of the best available internal capabilities, knowledge and skills in the service realization process. To this end, our study leads us to the conclusion that to leverage business value, it is important to understand how the IS organization gains access to and makes use of the best available resources.

The crucial resources from the business value perspective are both resident in the organization and held by external parties. Hence, they are not under the direct control of the IS organization. As efficient use of resources (Barney, 1991) is arguably one of the drivers of efficiency in economic activity, it can also be considered a key determinant of business value creation. The recent service management literature emphasizes the use of best available resources, which are often external to an organization. According to Vargo and Lusch (2008), the application of external knowledge and skills is the basis of all economic exchange. This is a fundamental principle of the S-DL of operation. In the IT service management sphere, the selection and acquisition of external IT capabilities are among the most decisive activities of the IS organization. From the business value perspective, our study shows that identification of the involved parties' capabilities in the early phases of IT service process is a crucial task in service system coordination.

In conclusion, our observations give rise to a new recipe for IS managers when orchestrating value co-creation in IT service processes. On the basis of our findings, we conceptualize principles for IS managers to bear in mind. These principles are summed up in Table 2 . In practice, orchestrating a complex service system for value creation through IT is often difficult. Most large organizations bring in consultants to perform this sort of bridging function. However, we see this as problematic, because the maintenance of a successful

Table 2 Principles for business value creation in multi-actor IT service systems

\begin{tabular}{|c|c|}
\hline Domain & Principles \\
\hline Mutual interests & $\begin{array}{l}\text { Link the essential stakeholders to the } \\
\text { IT-business dialogue by engrossing them to } \\
\text { each relevant encounter } \\
\text { Catalyze direct social interaction between } \\
\text { the stakeholders throughout the service } \\
\text { development process }\end{array}$ \\
\hline Power structure & $\begin{array}{l}\text { Create an equal opportunity for all } \\
\text { stakeholders to incorporate their needs } \\
\text { into a joint vision } \\
\text { Maintain consensus of the overall objectives } \\
\text { of the IT service by network leadership and } \\
\text { coordination }\end{array}$ \\
\hline $\begin{array}{l}\text { Knowledge } \\
\text { integration }\end{array}$ & $\begin{array}{l}\text { Master the infusion of both internal and } \\
\text { external knowledge and skills for improved } \\
\text { service } \\
\text { Avoid 'false consensus' by making the } \\
\text { resource integration open to all actors }\end{array}$ \\
\hline
\end{tabular}

business-IT dialogue is arguably one of the core activities of the internal IT organization. That is, the key tasks of an IS organization in business value creation include bringing together the participants' rightful needs and fostering their emancipative activity in order to effectuate value for all parties.

\section{Limitations and avenues for further research}

Our findings add to the previous research on IT and service management, as well as to the IT service management practice, but no study is free from limitations. We believe that the extent to which IT managers can learn to manage the entire IT service system to co-create value with multiple stakeholders will ultimately determine the success or failure of the IS organization in keeping its promises. However, future research may extend this study in several ways.

One of our main arguments is based on the concept of 'user perceived value'. We proposed that the perceived value in the service realization is key to generating outputs with business value to the organization. However, we did not systematically measure the satisfaction or value as perceived by the different stakeholders at each process phase. The IS organizations in the case settings did not measure these items, either. The problem is that perceptions are difficult and costly to evaluate. Such evaluation should comprise both quantitative and qualitative measurements. Future studies should more thoroughly investigate the connection between user-perceived value and output business value in IT services.

Although we focused on a certain multi-actor service system in only two case organizations, we acknowledge that the system may be connected to other parties that together constitute even larger and more complex service systems. Depending on how decentralized the IT function, there can be several similar bundles of IT, users, decision makers, and vendors. It should be noted that the intent of this paper is not to take a reductionist approach in stating that the findings from this bundle of actors remain the same when reintegrated to the entire service system or even to a greater service sphere. Instead, we see value in a meticulous description of how service was created and delivered through social action in specific organizational settings. More research is needed to understand value creation in larger service systems and in more complex organizational configurations.

In addition, the present study investigated IT service realization in a small geographical area in Northern Europe. Management and interaction cultures in the selected case organizations may differ from those in other organizations, countries, or cultures. Thus, the emphasis on the social action may vary among service systems. Future research may extend this study by testing the findings in different industries and in countries with different management cultures. Therefore, we call for more research to confirm and compare the identified tasks and roles of the stakeholder groups in the servicerealization process in addition to the structural configurations of IT service systems.

\section{Acknowledgements}

The authors wish to acknowledge the helpful comments of the special issue editor and the developmental critique of the anonymous reviewers. Their comments helped to improve the clarity of the paper as well as the precision of the contribution. 


\section{References}

Armstrong, C.P. and Sambamurthy, V. (1999). Information Technology Assimilation in Firms: The influence of senior leadership and IT infrastructures, Information Systems Research 10(4): 304-327.

Badinelli, R., Barile, S., Ng, I., Polese, F., Saviano, M. and Di Nauta, P. (2012). Viable Service Systems and Decision Making in Service Management, Journal of Service Management 23(4): 498-526.

Barki, H. and Hartwick, J. (1989). Rethinking the Concept of User Involvement, MIS Quarterly 13(1): 53-63.

Barney, J. (1991). Firm Resources and Sustained Competitive Advantage, Journal of Management 17(1): 99-120.

Berger, P.L. and Luckmann, T. (1967). The Social Construction of Reality: A treatise in the sociology of knowledge, London: Penguin.

Bitner, M., Faranda, W.T., Hubbert, A.R. and Zeithaml, V.A. (1997). Customer Contributions and Roles in Service Delivery, International Journal of Service Industry Management 8(3): 193-205.

Blazevic, V. and Lievens, A. (2008). Managing Innovation Through Customer Coproduced Knowledge in Electronic Services: An exploratory study, Journal of the Academy of Marketing Science 36(1): 138-151.

Borgatti, S.P. and Foster, P.C. (2003). The Network Paradigm in Organizational Research: A review and typology, Journal of Management 29(6): 991-1013.

Bowman, C. and Ambrosini, V. (2000). Value Creation vs Value Capture: Towards a coherent definition of value in strategy, British Journal of Management 11(1): 1-15.

Chandler, J. and Vargo, S. (2011). Contextualization and Value-in-Context: How context frames exchange, Marketing Theory 11(1): 35-49.

Clark, Jr. T.D., Jones, M.C. and Armstrong, C.P. (2007). The Dynamic Structure of Management Support Systems: Theory development, research focus, and direction, MIS Quarterly 31(3): 579-615.

Deighton, J. and Grayson, K. (1995). Marketing and Seduction: Building exchange relationships by managing social consensus, Journal of Consumer Research 21(4): 660-676.

Dubois, A. and Gadde, L.-E. (2002). Systematic Combining: An abductive approach to case research, Journal of Business Research 55(7): 553-560.

Eckerson, W.W. (2010). Performance Dashboards: Measuring, monitoring, and managing your business, Hoboken, NJ: John Wiley \& Sons.

Edvardsson, B., Tronvoll, B. and Gruber, T. (2011). Expanding Understanding of Service Exchange and Value Co-creation: A social construction approach, Journal of the Academy of Marketing Science 39(2): 327-339.

Fincham, R. (1992). Perspectives on Power: Processual, institutional and 'internal' forms of organizational power, Journal of Management Studies 29(6): $741-760$.

Gassmann, O., Enkel, E. and Chesbrough, H.W. (2010). The Future of Open Innovation, ReD Management 40(3): 213-221.

Gordon, S.R. and Gordon, J.R. (2002). Organizational Options for Resolving the Tension Between IT Department and Business Units in the Delivery of IT Services, Information Technology \& People 15(4): 286-305.

Groen, B.A.C., Van de Belt., M. and Wilderom, C.P.M. (2012). Enabling Performance Measurement in a Small Professional Service Firm, International Journal of Productivity and Performance Management 61(8): 839-862.

Grover, V. and Kohli, R. (2012). Cocreating IT Value: New capabilities and metrics for multifirm environments, MIS Quarterly 36(1): 225-232.

Grönroos, C. and Ravald, A. (2011). Service as Business Logic: Implications for value creation and marketing, Journal of Service Management 22(1): 5-22.

Grönroos, C. (2008). Service Logic Revisited: Who creates value? And who co-creates? European Business Review 20(4): 298-314.

Guillemette, M.G. and Paré, G. (2012). Toward a New Theory of The Contribution of The IT Function in Organizations, MIS Quarterly 36(2): 529-551.

Heiskanen, A., Newman, M. and Eklin, M. (2008). Control, Trust, Power, and the Dynamics of Information System Outsourcing Relationships: A process study of contractual software development, The Journal of Strategic Information Systems 17(4): 268-286.

Hirschheim, R. and Klein, H.K. (1989). Four Paradigms of Information Systems Development, Communications of the ACM 32(10): 1199-1216.

Hirschheim, R., Klein, H.K. and Newman, M. (1991). Information Systems Development as Social Action: Theoretical perspective and practice, Omega 19(6): 587-608.

Hirschheim, R.A. (1983). Assessing Participative Systems Design: Some conclusions from an exploratory study, Information \& Management 6(6): 317-327.
Ives, B. and Olson, M.H. (1984). User Involvement in MIS Success: A review of research, Management Science 30(5): 586-603.

Keen, P.G.W. (1993). Information Technology and the Management difference: A fusion map, IBM Systems Journal 32(1): 17-39.

Klein, H.K. and Myers, M.D. (1999). Set of Principles for Conducting and Evaluating Interpretive Field Studies in Information Systems, MIS Quarterly 23(1): 67-93.

Kohli, R. and Grover, V. (2008). Business Value of IT: An essay on expanding research directions to keep up with the times, Journal of the association for information systems 9(1): 23-39.

Lee, J.-N., Shaila, M.M. and Kim, Y.-M. (2004). IT Outsourcing Strategies: Universalistic, contingency, and configurational explanations of success, Information Systems Research 15(2): 110-131.

Lindgreen, A. and Wynstra, F. (2005). Value in Business Markets: What do we know? Where are we going? Industrial Marketing Management 34(7): 732-748.

Locke, E.A. and Schweiger, D.M. (1979). Participation in Decision-Making: One more look, Research in Organizational Behavior 1(10): 265-339.

Luftman, J. and Brier, T. (1999). Achieving and sustaining business-IT alignment, California Management Review 42(1): 109-122.

Lusch, R.F., Vargo, S.L. and O'Brien, M. (2007). Competing Through Service: Insights from service-dominant logic, Journal of Retailing 83(1): 5-18.

Maglio, P.P. and Spohrer, J. (2008). Fundamentals of Service Science, Journal of the Academy of Marketing Science 36(1): 18-20.

Markus, M.L. (2004). Technochange Management: Using IT to drive organizational change, Journal of Information Technology 19(1): 4-20.

Markus, M.L. and Robey, D. (1988). Information Technology and Organizational Change: Causal structure in theory and research, Management Science 34(5): 583-598.

Mathiassen, L. and Sørensen, C. (2008). Towards a Theory of Organizational Information Services, Journal of Information Technology 23(4): 313-329.

Mintzberg, H. (1983). Power in and Around Organizations, Englewood Cliffs, NJ: Prentice-Hall.

Mumford, E. (1979). Consensus Systems Design: An evaluation of this approach, in N. Szyperski and E. Grochla (eds.) Design and Implementation of Computer Based Information Systems, Groningen, Holland: Sijthoff and Noordhoff.

Myers, M.D. and Newman, M. (2007). The Qualitative Interview in IS Research: Examining the craft, Information \& Organization 17(1): 2-26.

Newell, S., Tansley, C. and Huang, J. (2004). Social Capital and Knowledge Integration in an ERP Project Team: The importance of bridging and bonding, British Journal of Management 15(1): 43-57.

Newman, M. and Robey, D. (1992). A Social Process Model of User-Analyst Relationships, MIS Quarterly 16(2): 249-266.

Nudurupati, S.S., Bititci, U.S., Kumar, V. and Chan, F. (2011). State of the Art Literature Review on Performance Measurement, Computers \& Industrial Engineering 60(2): 279-290.

Orlikowski, W. and Gash, D. (1994). Technological Frames: Making sense of information technology in organizations, ACM Transactions on Information Systems 12(2): 174-207.

Orlikowski, W.J. and Baroudi, J. (1990). Studying Information Technology in Organisations: Research approaches and assumptions, Information Systems Research 2(1): 1-28.

Pauwels, K., Ambler, T., Clark, B.H., LaPointe, P., Reibstein, D., Skiera, B. Wierenga, B. and Wiesel, T. (2009). Dashboards as a Service: Why, what, how, and what research is needed? Journal of Service Research 12(2): 175-189.

Peñaloza, L. and Venkatesh, A. (2006). Further Evolving the New Dominant Logic of marketing: From services to the social construction of markets, Marketing Theory 6(3): 299-316

Peppard, J. (2003). Managing IT as a Portfolio of Services, European Management Journal 21(4): 467-483.

Peppard, J.W. and Ward, J.M. (2005). Unlocking Sustained Business Value from IT Investments, California Management Review 48(1): 52-70

Qiu, R.G. (2009). Computational Thinking of Service Systems: Dynamics and adaptiveness modeling, Service Science 1(1): 42-55.

Ramirez, R. (1999). Value Co-production: Intellectual origins and implications for practice and research, Strategic Management Journal 20(1): 49-65.

Sambamurthy, V. and Zmud, R.W. (1999). Arrangements for Information Technology Governance: A theory of multiple contingencies, MIS Quarterly 23(2): 261-290 
Sandström, S., Edvardsson, B., Kristensson, P. and Magnusson, P. (2008). Value in use Through Service Experience, Managing Service Quality 18(2): 112-126.

Sarker, S., Sarker, S., Sahaym, A. and Bjørn-Andersen, N. (2012). Exploring Value Cocreation in Relationships Between an ERP Vendor and Its Partners: A revelatory case study, MIS Quarterly 36(1): 317-338.

Sawhney, M. and Parikh, D. (2001). Where Value Lives in a Networked World, Harvard Business Review 79(1): 79-90.

Sierra, J.J. and McQuitty, S. (2005). Service Providers and Customers: Social exchange theory and service loyalty, Journal of Services Marketing 19(6): 392-400. Standifer, R.L. and Wall, J.A.J. (2003). Managing Conflict in B2B E-Commerce, Business Horizons 46(2): 65-70.

Stucky, S., Cefkin, M., Rankin, Y., Shaw, B. and Thomas, J. (2011). Dynamics of Value Co-creation in Complex IT Service Engagements, Information Systems \& E-Business Management 9(2): 267-281.

Vargo, S.L. and Lusch, R.F. (2004). Evolving to a New Dominant Logic for Marketing, Journal of Marketing 68(7): 1-17.

Vargo, S.L. and Lusch, R.F. (2008). Service-Dominant Logic: Continuing the evolution, Journal of the Academy of Marketing Science 36(1): 1-10.

Venkatraman, N. and Loh, L. (1993). The Shifting Logic of the IS Organization: From technical portfolio to relationship portfolio, Information Strategy: The Executive's Journal 10(2): 5-12.

Walsham, G. (1995). Interpretive Case Study in IS Research, Nature and method European Journal of Information Systems 4(2): 74-81.

Weill, P. (2004). Don't Just Lead, Govern: How top-performing firms govern IT, MIS Quarterly Executive 3(1): 1-17.

Weill, P. and Ross, J.W. (2005). A Matrixed Approach to Designing IT Governance, Sloan Management Review 46(2): 26-34.

Xia, W. and Lee, G. (2005). Complexity of Information Systems Development Projects: Conseptualization and measurement development, Journal of Management Information Systems 22(1): 45-83.

Yun Kyung, C. and Menor, L.J. (2010). Toward a Provider-Based View on the Design and Delivery of Quality E-Service Encounters, Journal of Service Research 13(1): 83-95.

Zeithaml, V.A., Parasuraman, A. and Berry, L.L. (1985). Problems and Strategies in Services Marketing, Journal of Marketing 49(2): 33-46.

\section{About the Authors}

Heikki Lempinen holds a Ph.D in Information Systems Science from the Aalto University School of Business. His research is centered on information systems design, IT services, business analytics and performance management. His work has so far appeared in the International Journal of Organizational Design and Engineering, and in several academic conferences, including the European Conference on Information Systems, Design Science Research in Information Systems and Technologies (DESRIST), and the Scandinavian Conference on Information Systems. Besides his postdoctoral research, Dr. Lempinen is currently affiliated with a leading European online fashion retailer where he works in a business development role.

Risto Rajala is an assistant professor in the Department of Industrial Engineering and Management at the Aalto University School of Science. He holds a Ph.D in Information Systems Science from the Aalto University School of Business. His recent research has dealt with management of complex service systems, institutional change in service organizations, development of digital services, service innovation and business model performance. Dr. Rajala's areas of specialization include management of industrial services, collaborative service innovation, knowledge management and design of digital services. His work has been published widely in refereed scientific journals, including Industrial Marketing Management, California Management Review, European Journal of Marketing, Management Learning, International Journal of Technology Management, and Journal of Systems and Information Technology.

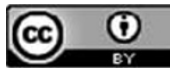

This work is licensed under a Creative Commons Attribution 3.0 Unported License. To view a copy of this license, visit http://creativecommons.org/ licenses/by/3.0/ 